\title{
Chapter 17 \\ Sustainability Assessment of Sanitary \\ Ware Supply Chain Using Life Cycle Assessment Framework-A Case Study
}

\author{
Kuldip Singh Sangwan 10 , Kailash Choudhary, and Shilpi Agarwal
}

\begin{abstract}
Sanitary wares are the integral part of construction materials but there is hardly any study in the literature which shows the environmental impacts from the sanitary ware. This paper aims at assessing sustainability of a ceramic sanitary ware supply chain by quantifying the environmental impacts from materials and resources used throughout the different phases of a sanitary ware life cycle. The impacts are quantified using ReCiPe endpoint and midpoint assessment methods with Umberto NXT Software and eco-invent 3.0 database. This study uses climate change, fossil depletion, human toxicity, metal depletion, ozone depletion, terrestrial acidification, water depletion, damage to ecosystem quality, human health, and resources assessment categories to quantify the environmental impacts. The life cycle assessment finds that consumption of heavy fuel oil, electricity, grass, and cement mortar is primarily responsible for the negative impacts on the environment. It is also found that manufacturing and transportation phases of the supply chain have maximum contribution to the environmental degradation. The methodology, assessment methods and impact categories used in the study can be used by the other ceramic enterprises for the identification and benchmarking of environmental hotspots in their supply chains. It is expected that this study will be useful for the policy makers as well as the manufacturer to find the key areas for decreasing the environmental impacts and enhancing sustainability of a sanitary ware supply chain.
\end{abstract}

Keywords Life cycle assessment $\cdot$ Sustainability assessment $\cdot$ Ceramic sanitary ware

K. S. Sangwan $(\varangle) \cdot$ S. Agarwal

Birla Institute of Technology and Science, Pilani 333031, India

e-mail: kss@ pilani.bits-pilani.ac.in

K. Choudhary

Mody University of Science and Technology, Lakshmangarh, India

(C) The Author(s) 2020

K. S. Sangwan and C. Herrmann (eds.), Enhancing Future Skills and Entrepreneurship,

Sustainable Production, Life Cycle Engineering and Management,

https://doi.org/10.1007/978-3-030-44248-4_17 


\subsection{Introduction}

Sustainable construction has started getting researchers' and policy makers' attention because of high amount of energy and resource consumption by construction sector. The construction sector is responsible for the $40 \%$ energy and $30 \%$ raw material consumption worldwide. The construction sector is responsible for the $25 \%$ of the world's solid waste generation and the ceramic waste contributes highest to this. The sanitary ware market is driven by the increasing standards of living, growing real estate industry, and increasing population in the developing countries. The ceramic sanitary ware market is estimated to record a compound annual growth rate (CAGR) of $10.3 \%$ between 2016 and 2026. The Indian sanitary ware market share accounts for $8 \%$ of the global production and stands at second rank in terms of volume in the Asia-Pacific region. In India, around 69\% households in rural areas and about $19 \%$ households in urban areas still do not have access to safe sanitation (http://www.gima.de/media/1/1/4798/overview_of_india_ s_bathroom_kitchen_industry.pdf). This provides an opportunity in term of sanitary ware market growth but it is also a cause of worry from the environmental perspective because of large quantity of natural resource extraction and waste generation along the supply chain of a sanitary ware.

The processes used in the production of ceramics are broadly divided into three groups; namely, pre kiln, kiln and post kiln processes. The major pre kiln processes contain ball milling, blunging, mixing, casting, drying, cleaning, and glazing. The pre kiln waste is called green waste, as this is recyclable without any difficulty. Generally, the green waste is $40 \%$ of the green product weight. The green products are then fired in the kiln to provide strength. Any rejection/waste after kiln firing (post kiln) is non-recyclable. The major problems faced by the ceramic industry are large rejections and poor quality. The large rejections, particularly after kiln firing, cause environmental issues and problems of land occupation. The current choice to dispose off the ceramic waste is landfill (Bhamu and Sangwan 2015).

Life cycle assessment (LCA) is a tool to assess, compare and benchmark the environmental impacts associated with pre-manufacturing, manufacturing and postmanufacturing phases of a product. Generally, the LCA studies are carried out with different scopes: cradle to cradle, cradle to grave, cradle to gate, and gate to gate. The LCA concept came into existence during 1970-90 but the standardization of approaches and terminologies took place during 1990-2000 (Guinee et al. 2011). There are a few papers in literature showing the environmental impact assessment from the construction materials, and construction \& demolition (C\&D) waste (Ye et al. 2018; Özkan et al. 2016; Sangwan et al. 2018) but none of these studies has focus on assessment of environmental impact due to sanitary ware products. Thus, the objective of this study is to assess and map the environmental impacts of different phases, processes, and materials used throughout the product life cycle including end of life disposal (pre-manufacturing, manufacturing, and post-manufacturing). 
The next section of study presents the background of the selected topic. Section 17.3 presents the materials and methods used in the study. Section 17.4 shows the observed results and discussion. Section 17.5 explains the practical implications of the findings and the study ends with conclusions in Sect. 17.6.

\subsection{Background}

There are two schools of thought to assess the environmental impacts arising out during a product's life cycle. One school uses the knowledge of professionals to assess the environmental impacts using survey based empirical investigations (Mittal and Sangwan 2014). This is a simple method but does not provide the quantified environmental impacts generated during a product life cycle. The second school of thought provides quantitative emission results which can be easily attributed to the resources and materials used during different phases of a product life cycle (Ye et al. 2018; Özkan et al. 2016; Sangwan et al. 2018). This method is more exhaustive but requires lots of quantitative data for the assessment. The assessment can show a product's environmental impact in terms of climate change potential, freshwater ecotoxicity potential, freshwater eutrophication potential, marine ecotoxicity potential, marine eutrophication potential, terrestrial acidification potential, terrestrial eutrophication potential, fossil depletion potential, human toxicity potential, metal depletion potential, ozone depletion potential, particulate matter formation potential, terrestrial acidification potential, agriculture land occupation, urban land occupation, ionizing radiation, natural land transformation, photochemical oxidant formation, and water depletion potential. The possible assessment methods to calculate the environmental impacts using different LCA tools are: ReCiPe endpoint, ReCiPe midpoint, CML2001, impact2002+ , EDIP2003, and ecoindicator99 (Rebitzer et al. 2004). LCA provides the environmental hotspots along the supply chain, therefore remedial measures are much more effective to control the environmental impacts. This paper belongs to the second school of thought.

A few studies have been done to assess the environmental impacts generated during the production of construction materials. Ye et al. (2018) conducted a cradle to gate life cycle assessment and life cycle cost analysis for ceramic tile manufacturing in China. The results show that major environmental impacts are in terms of marine ecotoxicity, climate change, terrestrial ecotoxicity, human toxicity, and fossil depletion. The study observes that the use of inorganic chemicals and coalbased electricity are the main factors contributing to the generation of environmental impacts. Özkan et al. (2016) conducted a cradle to gate life cycle assessment study for the refractory bricks. The study found that the production of raw materials and firing process are the main contributors to the environmental impacts. Balasbaneh et al. (2018) conducted sustainability assessment to find the environmental friendly design alternate among the different options for wall and roof construction using 
LCA. Sangwan et al. (2018) assesses the environmental impacts in terms of midpoint and endpoint categories during the different life cycle phases, from material and resources consumed along a ceramic tile supply chain. The study identifies that manufacturing phase generates highest environmental impacts due to the use of red oxide in glaze preparation, electricity consumed in kiln, and film used in packaging. Bribián et al. (2011) conducted an LCA of different construction materials (steel, cement, ceramics, mortar, wood, etc.). The study identified that ceramics materials in construction account for $21.5 \%$ of the energy consumption and $20.3 \%$ of $\mathrm{CO}_{2}$ emissions. This is due to the electricity and natural gas consumption in the kiln process. Cabeza et al. (2014) presents the review of the studies related to life cycle assessment, life cycle energy analysis, and life cycle cost analysis for building and building related industries. The review shows that there are only few studies on the life cycle assessment of the construction materials, their production and selection.

The literature shows the importance of quantification and assessment of the environmental impacts from the different materials required in the construction industry. But there is hardly any study which shows the environmental impacts from the supply chain of ceramic sanitary wares. This study tries to fill this gap by quantifying and assessing the environmental impacts during the different life cycle phases, processes, resources, and materials in a sanitary ware supply chain.

\subsection{Materials and Method}

Environmental impacts from sanitary ware supply chain have been assessed using LCA framework based on ISO 14040 series guidelines using primary and secondary data (Rebitzer et al. 2004). The LCA framework uses four steps. In the first step; study goal, scope and functional unit are defined. This is followed by the collection of inventory data for the study. Next, impact assessment is done using LCA software followed by the interpretation of the results.

\subsubsection{Goals and Scope}

The goals of this study are to:

I. Assess the environmental impacts from a sanitary ware supply chain.

II. Compare the environmental impacts caused in different phases due to consumption of different materials and resources along the product life cycle.

A cradle to grave approach has been used, which comprises of raw material extraction, manufacturing, transportation, installation, and disposal phases (Rebitzer et al. 2004). Use phase is excluded due to the lack of data availability. The functional unit considered for this study is a standard washbasin weighing $14 \mathrm{~kg}$. Machine life in manufacturing phase is assumed to be 20 years. Process flow in Fig. 17.1 shows 


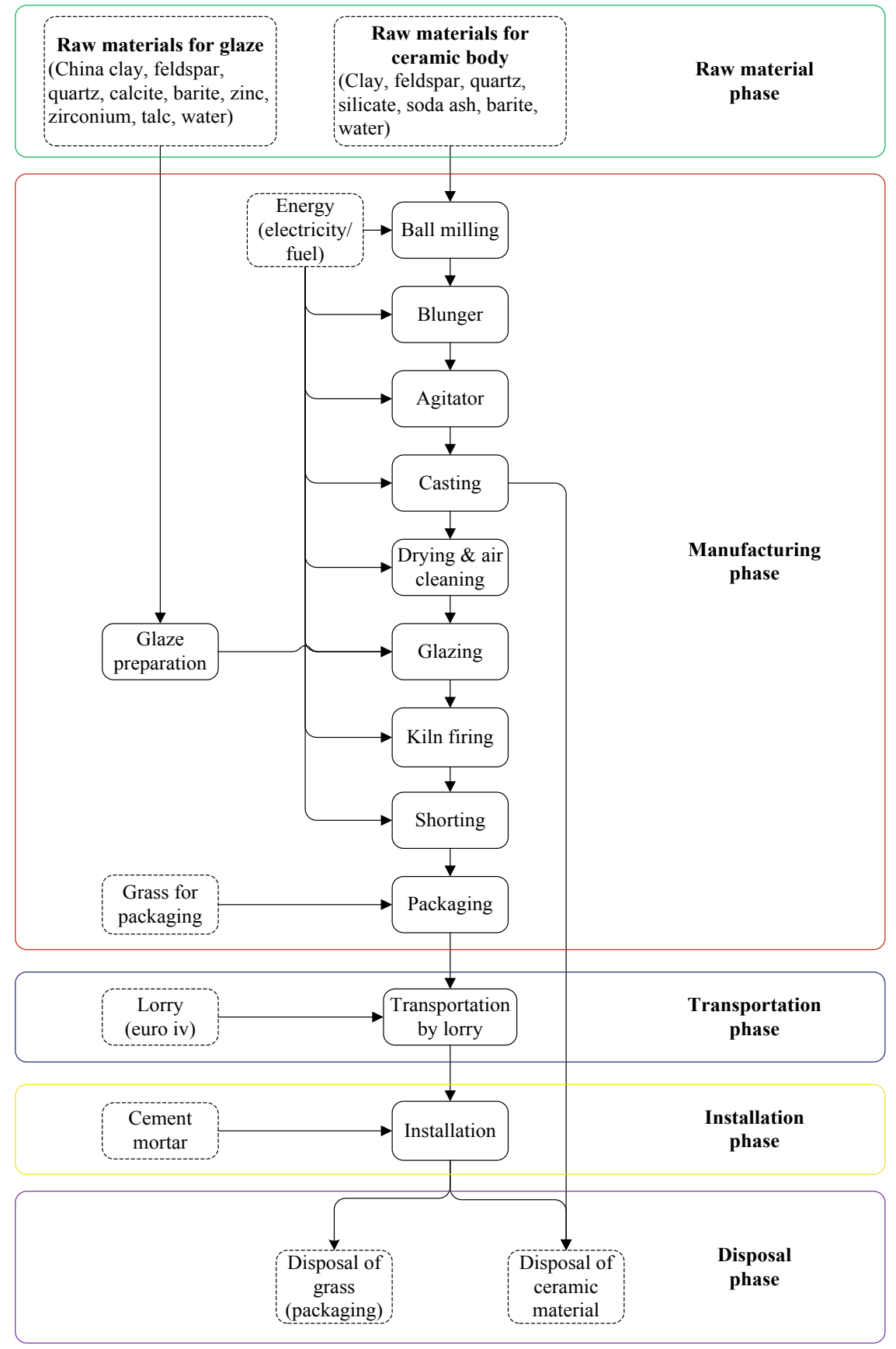

Fig. 17.1 Process flow of sanitary ware supply chain with different phases and processes 
Table 17.1 Primary inventory data for one sanitary ware product (14 kg standard washbasin)

\begin{tabular}{l|l}
\hline Processes & Materials/resource, energy, and emissions \\
\hline Ball milling & Clay $9.1 \mathrm{~kg}$, Feldspar $3.5 \mathrm{~kg}$, Quartz $0.7 \mathrm{~kg}$, Silicate $0.056 \mathrm{~kg}$, Soda Ash \\
& $0.028 \mathrm{~kg}$, Barite $0.007 \mathrm{~kg}$, Water 6.31 , electricity $0.088 \mathrm{kwh}$ \\
\hline Blunzer & Soda Ash $0.021 \mathrm{~kg}$, Silicate $0.042 \mathrm{~kg}$, Water 4.21 , electricity $0.081 \mathrm{kwh}$ \\
\hline Casting (POP Mold) & Gypsum $0.4 \mathrm{~kg}$, Water 0.211, Solid waste $0.61 \mathrm{~kg}$ \\
\hline Glaze preparation & Feldspar $0.072 \mathrm{~kg}$, Quartz $0.036 \mathrm{~kg}$, Calcite $0.026 \mathrm{~kg}$, China Clay \\
& $0.012 \mathrm{~kg}$, Barite $0.004 \mathrm{~kg}$, Zinc $0.006 \mathrm{~kg}$, Zirconium $0.024 \mathrm{~kg}$, Talc \\
& $0.001 \mathrm{~kg}$, Water 0.0721 , electricity $0.001 \mathrm{kwh}$ \\
\hline Kiln firing & Heavy fuel oil 1.031 , electricity $0.41 \mathrm{kwh}$ \\
\hline Packaging & Grass $0.92 \mathrm{~kg}$ \\
\hline Installation & Mortar $4.75 \mathrm{~kg}$, packaging waste $0.92 \mathrm{~kg}$, Solid waste $14 \mathrm{~kg}$ (after use) \\
\hline Total electricity & $0.8 \mathrm{kwh}$ (in all processes) \\
\hline
\end{tabular}

the scope of the study and major processes in this supply chain. The Umberto model is developed after carefully studying the processes and supply chain of a sanitary ware manufacturer. The developed model used for the calculations of environmental impacts contains the detailed information of processes, materials and resources used in the supply chain. Unlike the developed Umberto model, process flow diagram (Fig. 17.1) shows only major processes in the supply chain.

\subsubsection{Inventory Analysis}

A case study was conducted at one of the manufacturers of sanitary ware products located in industrial area of Bikaner city in India. This manufacturer, a medium scale enterprise, supplies sanitary ware to the northern part of India. The sanitary ware production process is standard. One of the authors studies the manufacturing process at the site to get the average of the inventory data. This primary data contains the quantity of raw materials (clay, feldspar, quartz, etc.), water, fuel, and electricity used along the supply chain as shown in Table 17.1. Secondary data for upstream activities (raw material extraction, electricity, fuel, machine consumption, and water supply) and downstream activities (ceramic waste disposal and packaging waste disposal) is taken from eco-invent 3.0 database.

\subsubsection{Impact Assessment}

Umberto NXT software with eco-invent 3.0 database is used for environmental impact assessment using ReCiPe endpoint and ReCiPe midpoint assessment methods. The ReCiPe method is selected from the other available methods of life cycle 
impact assessment (LCIA) because this is a newly developed method on the concepts of CML 2001 and eco-indicator 99. This method harmonizes the existing midpoint and endpoint assessment methods and eliminates the barrier of LCIA method selection in design and analysis of LCA as pointed out by Dong and $\mathrm{Ng}$ (2014). The impact categories considered in this study for ReCiPe endpoint assessment are damage to ecosystem quality, human health, and resources; and climate change $\left(\mathrm{kg} \mathrm{CO}_{2}-\mathrm{Eq}\right)$, fossil depletion (kg oil-Eq), human toxicity (kg 1,4-DCB-Eq), metal depletion ( $\mathrm{kg}$ Fe-Eq), ozone depletion (kg CFC-11-Eq), terrestrial acidification ( $\left.\mathrm{kg} \mathrm{SO}_{2}-\mathrm{Eq}\right)$, and water depletion $\left(\mathrm{m}^{3}\right)$ for ReCiPe midpoint assessment.

\subsection{Results and Discussion}

The results of the environmental impacts from materials and resources used throughout the different phases of a sanitary ware life cycle are presented here.

\subsubsection{Endpoint Assessment}

The Fig. 17.2 show the environmental impact assessment using ReCiPe endpoint assessment method. It depicts the impact from various phases (i.e. raw material extraction, manufacturing, transportation, installation, and disposal) in the categories of ecosystem quality, human health, and resources. As shown in Fig. 17.2, manufacturing phase has the maximum effect on ecosystem quality (5.40 points) and resources (12.50 points) followed by transportation phase, which have 4.51 points and 8.34 points impacts in same categories. The maximum impact in manufacturing phase is due to the resource consumption. However, transportation phase (8.23 points) has the highest impact on human health followed by manufacturing phase (6.34 points). The major impacts in human health during transportation phase may be attributed to the release of toxic gases like carbon monoxide, sulfur dioxide and nitrogen oxides

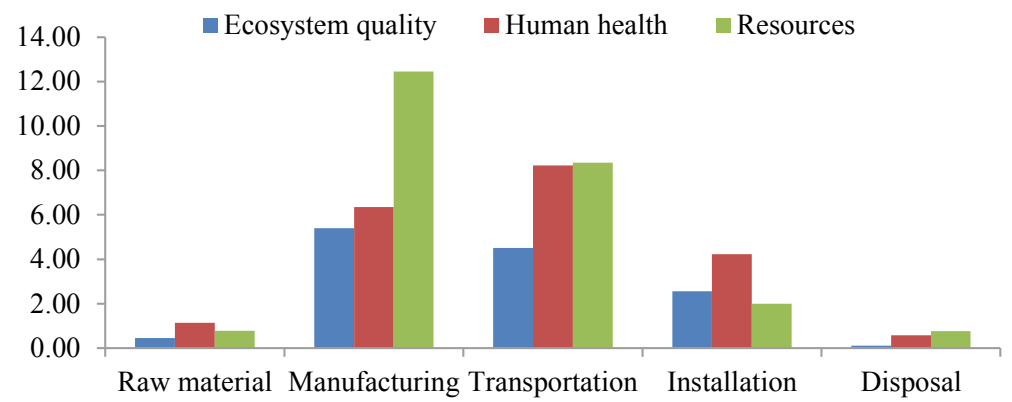

Fig. 17.2 Endpoint environmental impacts in different phases 
due to the burning of fuel. The effects of installation phase, though less than manufacturing and transportation phases, are still significant. Installation phase have 2.55 points impacts on ecosystem quality, 4.23 points impacts on human health, and 1.99 point impacts on resource depletion. Raw material extraction phase has very low effect on the endpoint categories (ecosystem quality 0.46 points, human health 1.14 points, and resource depletion 0.78 point) and the disposal phase has negligible effect (ecosystem quality $=0.11$ points, human health $=0.58$ points, and resource depletion $=0.76$ point). This is because the disposal of sanitary ware does not produce any harmful or toxic emissions in any form. Moreover, sanitary ware manufacturer avoids use of redoxide during glazing, which further reduces the environmental impacts in raw material and disposal phases.

Figure 17.3 shows the environmental impact assessment using ReCiPe endpoint assessment method for the used resources during the life cycle of a sanitary ware. It shows the impact for various materials, energy and facilities (feldspar, clay, heavy fuel oil, inert waste, grass, electricity, industrial machine, transport, etc.) on the three endpoint impact categories. It shows that the impact caused by the manufacturing phase on ecosystem quality is mainly due to the use of grass in packaging (3.27 points) followed by electricity consumption ( 1.35 points) and heavy fuel oil fired in kiln (0.78 points). Impact caused by the manufacturing phase on human health is mainly due to the electricity consumption (3.41 points) followed by heavy fuel oil (1.48 points) and grass (1.46 points). Impact caused by the manufacturing phase on resources is mostly due to the heavy fuel oil usage (9.83 points). The studies conducted by Ye et al. (2018). Özkan et al. (2016), and Sangwan et al. (2018) observed similar results and identified that fuel for firing, electricity, and packaging material have high environmental impacts during the manufacturing phase of ceramic products.

Industrial machines used in the manufacturing phase have insignificant effect on the three categories. Cement mortar causes the impacts during the installation phase and inert waste in the disposal phase. All the materials in the raw material extraction phase (feldspar, ball clay, china clay, quartz, water, zirconium, zinc, soda ash, silicate, gypsum, and barite) have very low environmental impacts in the selected endpoint categories. The highest impact is due to the use of trucks in transportation of sanitary ware. The ceramic industries have clusters in specific region of India based on the

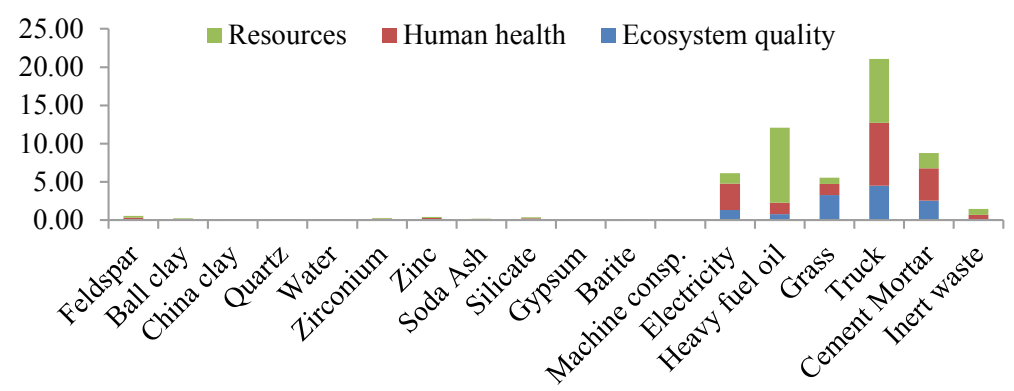

Fig. 17.3 Endpoint environmental impacts by different materials 


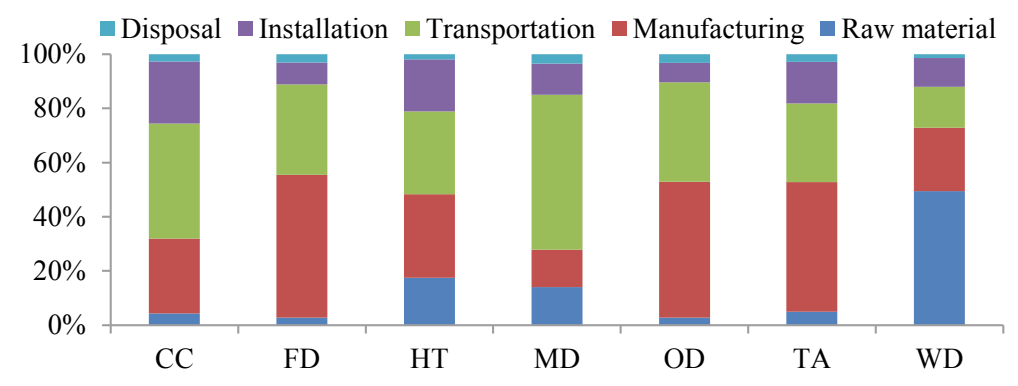

Fig. 17.4 Midpoint environmental impacts in different phases

availability of raw material. The transportation of products from these clusters is through trucks (lorries) which is not a sustainable option. The opening of future industries should be near to the market as the transportation of the raw material has much less environmental impact because of low volume compared to the finished goods.

\subsubsection{Midpoint Assessment}

Figure 17.4 show the environmental impact assessment using ReCiPe midpoint assessment method. It depicts the percentage-wise impact of each phase in the categories of climate change (CC), fossil depletion (FD), human toxicity (HT), metal depletion (MD), ozone depletion (OD), terrestrial acidification (TA), and water depletion (WD).

The major contributors in all the categories, except water depletion, are the manufacturing $\left(\mathrm{CC}=136 \mathrm{~kg} \mathrm{CO}_{2}-\mathrm{Eq}, \mathrm{FD}=115 \mathrm{~kg}\right.$ oil-Eq, $\mathrm{HT}=26.9 \mathrm{~kg}$ 1,4-DCB-Eq, $\mathrm{MD}=2.70 \mathrm{~kg} \mathrm{Fe}-\mathrm{Eq}, \mathrm{TA}=1.38 \mathrm{~kg} \mathrm{SO}_{2}-\mathrm{Eq}$, and $\left.\mathrm{WD}=0.34 \mathrm{~m}^{3}\right)$ and transportation phases $(\mathrm{CC}=209 \mathrm{~kg} \mathrm{CO}$-Eq, FD $=72.7 \mathrm{~kg}$ oil-Eq, HT $=26.7 \mathrm{~kg} 1,4-\mathrm{DCB}-$ $\mathrm{Eq}, \mathrm{MD}=11.40 \mathrm{~kg} \mathrm{Fe}-\mathrm{Eq}, \mathrm{TA}=0.84 \mathrm{~kg} \mathrm{SO}_{2}-\mathrm{Eq}$, and $\left.\mathrm{WD}=0.22 \mathrm{~m}^{3}\right) . \mathrm{In}$ water depletion category, raw material extraction phase $\left(0.72 \mathrm{~m}^{3}\right)$ contributes almost $50 \%$ environmental impact. Manufacturing phase contributes almost 50\% impact in fossil depletion (115 kg oil-Eq) and terrestrial acidification (1.38 kg SO $2-\mathrm{Eq})$ categories due to the use of electricity ( $\mathrm{FD}=16.7 \mathrm{~kg}$ oil-Eq and $\mathrm{TA}=0.45 \mathrm{~kg} \mathrm{SO}_{2}$-Eq) and heavy fuel oil $\left(\mathrm{FD}=91.1 \mathrm{~kg}\right.$ oil-Eq and TA $\left.=0.23 \mathrm{~kg} \mathrm{SO}_{2}-\mathrm{Eq}\right)$ in kiln firing. Transportation phase contributes almost $56 \%$ in metal depletion category $(\mathrm{MD}=11.4 \mathrm{~kg}$ $\mathrm{Fe}-\mathrm{Eq}$ ). Installation has around $26 \%$ impact on the climate change category (113 kg $\left.\mathrm{CO}_{2}-\mathrm{Eq}\right)$ due to use of mortar. Disposal phase has the least impact in all the seven categories $(\mathrm{CC}=13.2 \mathrm{~kg} \mathrm{CO}-\mathrm{Eq}, \mathrm{FD}=6.77 \mathrm{~kg}$ oil-Eq, $\mathrm{HT}=1.63 \mathrm{~kg}$ 1,4-DCB-Eq, $\mathrm{MD}=0.70 \mathrm{~kg} \mathrm{Fe}-\mathrm{Eq}, \mathrm{TA}=0.08 \mathrm{~kg} \mathrm{SO}_{2}-\mathrm{Eq}$, and $\mathrm{WD}=0.02 \mathrm{~m}^{3}$ ) because sanitary ware is an inert waste, which is not toxic and harmful. 


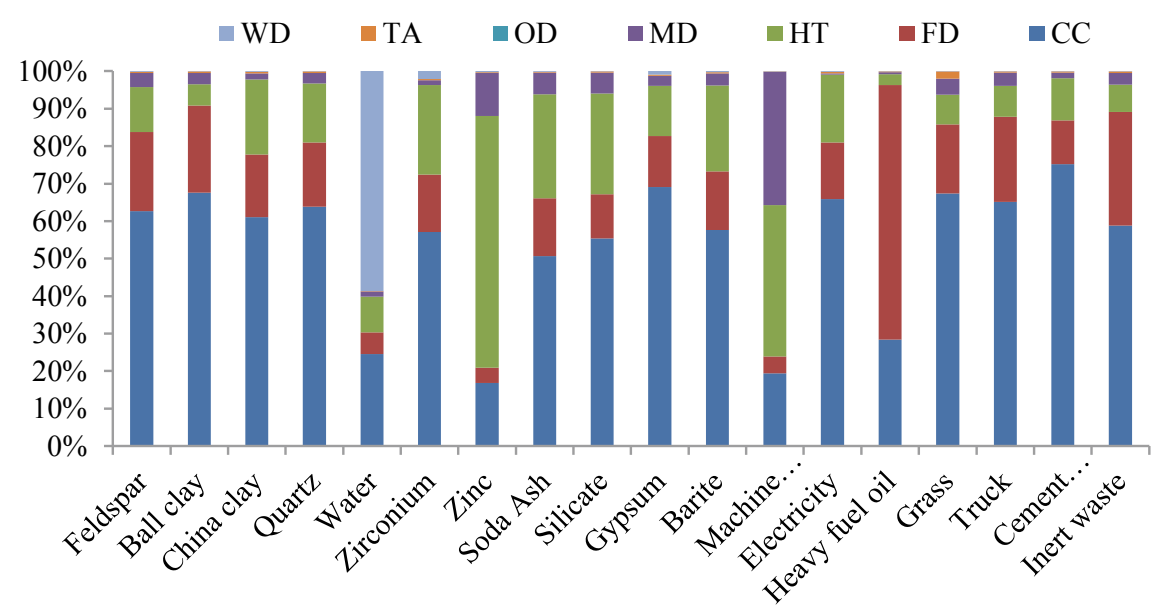

Fig. 17.5 Midpoint environmental impacts by different materials

The results of ReCiPe midpoint assessment method by different materials, energy and facilities are also shown in Fig. 17.5. It shows the percentage-wise contribution of the seven categories from various materials, energy and facilities used along the supply chain. The materials, energy and facilities (except water) have major impacts in climate change category.

Zinc contributes around $67 \%$ to human toxicity (9.21 kg 1,4-DCB-Eq), industrial machines contribute around $40 \%$ to human toxicity, and heavy fuel oil contributes around $67 \%$ to fossil depletion $(91.1 \mathrm{~kg}$ oil-Eq). Cement mortar used for installation of sanitary ware has the maximum climate change potential $\left(113 \mathrm{~kg} \mathrm{CO}_{2}\right.$-Eq). Industrial machines used in manufacturing phase cause the maximum depletion of metals.

However, Fig. 17.5 shows the effects in relative percentage term, it does not reflect the effect in absolute terms. The effect of industrial machines consumption only shows that the human toxicity, metal depletion and climate change are the main affected categories out of the seven categories. The total effect of machine consumption is almost negligible compared to other resources used.

\subsection{Practical Implications}

This study identifies that heavy fuel oil, packaging material, electricity consumption, cement mortar, and transport of the finished products are the hotspots of the environmental impacts in manufacturing, installation, and transportation phases. The findings of the study can be used by the policy makers to form the future strategies for this sector to reduce the environmental impacts. The findings of this study will 
generate awareness among the manufacturers of this sector and help the government to form the regulations for this sector. Awareness and legislation should be focused simultaneously for the reduction of environmental impacts from the construction sector. The future legislations should focus on the environmental friendly use and production of construction materials, establishment of new enterprises nearer to the market. Government should also conduct workshops and seminars to educate and aware the top management of the construction enterprises about the latest technologies, environmentally efficient processing, and efficient resource utilization to decrease the environmental impacts.

This study suggests the replacement of heavy fuel oil by natural gas in kiln firing, renewable energy source of electricity, and alternate material in packaging to reduce impact in the manufacturing phase. This study recommends replacing the cement from the mortar with marble slurry in certain percentage to reduce the environmental impacts during installation phase. There is a possibility to use ceramic waste in the production of concrete, therefore future research should be focused in this direction. This will help to reduce the use of virgin materials and also solve waste disposal problem of ceramic sector. The methodology, assessment methods and impact categories used in the study can be used by other ceramic enterprises for the identification of environmental hotspot in their supply chain. Also, the results of the study can be used by the different ceramic enterprises for benchmarking purpose.

\subsection{Conclusions}

This study has assessed, compared and analyzed the results of the environmental impacts caused in different phases by the materials and resources used in a sanitary ware supply chain. It is found that manufacturing and transportation phases have high environmental impacts followed by installation phase. The other two phases of this supply chain (raw material extraction and disposal) cause insignificant damage to the environment. It is also found, among the materials used throughout the supply chain, that heavy fuel oil, electricity, grass, and cement mortar cause maximum damage to the environment. Hence, this study will help the policy makers to act on the identified hot spots of environmental impacts in sanitary ware supply chain and take appropriate actions to develop future green strategies for this industry to enhance sustainability. These findings suggest that there is a need to focus on environmental efficiency in the manufacturing and transportation phases of the supply chain. Sanitary ware industries should be distributed around the country to reduce the environmental impact caused by transportation.

The limitation of this study is that the primary data has been collected from only one manufacturing plant in India. The study represents the whole sanitary ware supply chain by considering selected case enterprise as a focal firm. However, this study does not represent the multiplayers at the each stage of the supply chain. Future studies can consider more than one case and use this study for the benchmarking purpose. Also, the sanitary ware waste after useful life is taken as inert waste, which is nearest 
in properties in ecoinvent 3.0 database. This study does not consider transportation from retailers to customers because of complexity in data collection. Moreover, the distances involved in transportation from retailers to customers are comparatively negligible.

\section{References}

Balasbaneh AT, Bin Marsono AK, Kasra Kermanshahi E (2018) Balancing of life cycle carbon and cost appraisal on alternative wall and roof design verification for residential building. Construct Innov 18(3):274-300. https://doi.org/10.1108/CI-03-2017-0024

Bathroom \& Kitchen Expo Overview of India's Bathroom \& Kitchen Industry. http://www.gima. de/media/1/1/4798/overview_of_india_s_bathroom_kitchen_industry.pdf. Last assessed 13 Apr 2018

Bhamu J, Sangwan KS (2015) Reduction of post-kiln rejections for improving sustainability in ceramic industry: a case study. Procedia CIRP 26:618-623. https://doi.org/10.1016/j.procir.2014. 07.176

Bribián IZ, Capilla AV, Usón AA (2011) Life cycle assessment of building materials: comparative analysis of energy and environmental impacts and evaluation of the eco-efficiency improvement potential. Build Environ 46(5):1133-1140. https://doi.org/10.1016/j.buildenv.2010.12.002

Cabeza LF, Rincón L, Vilariño V, Pérez G, Castell A (2014) Life cycle assessment (LCA) and life cycle energy analysis (LCEA) of buildings and the building sector: a review. Renew Sustain Energy Rev 29:394-416. https://doi.org/10.1016/j.rser.2013.08.037

Dong YH, Ng ST (2014) Comparing the midpoint and endpoint approaches based on ReCiPe-a study of commercial buildings in Hong Kong. Int J Life Cycle Assess 19:1409-1423. https://doi. org/10.1007/s11367-014-0743-0

Guinee JB, Heijungs R, Huppes G, Zamagni A, Masoni P, Buonamici R, Ekvall T, Rydberg T (2011) Life cycle assessment: past, present, and future. Environ Sci Technol 45(1):90-96

Mittal VK, Sangwan KS (2014) Development of a structural model of environmentally conscious manufacturing drivers. J Manufact Technol Manage 25(8):1195-1208. https://doi.org/10.1080/ 00207543.2013.838649

Özkan A, Günkaya Z, Tok G, Karacasulu L, Metesoy M, Banar M, Kara A (2016) Life cycle assessment and life cycle cost analysis of magnesia spinel brick production. Sustainability (Switzerland) 8(7):1-13. https://doi.org/10.3390/su8070662

Rebitzer G, Ekvall T, Frischknecht R, Hunkeler D, Norris G, Rydberg T, Schmidt WP, Suh S, Weidema BP, Pennington DW (2004) Life cycle assessment Part 1: framework, goal and scope definition, inventory analysis, and applications. Environ Int 30(5):701-720. https://doi.org/10. 1016/j.envint.2003.11.005

Sangwan KS, Choudhary K, Batra C (2018) Environmental impact assessment of a ceramic tile supply chain—a case study. Int J Sust Eng 11(3):211-216. https://doi.org/10.1080/19397038. 2017.1394398

Ye L, Hong J, Ma X, Qi C, Yang D (2018) Life cycle environmental and economic assessment of ceramic tile production: a case study in China. J Clean Prod 189:432-441. https://doi.org/10. 1016/j.jclepro.2018.04.112 
Open Access This chapter is licensed under the terms of the Creative Commons Attribution 4.0 International License (http://creativecommons.org/licenses/by/4.0/), which permits use, sharing, adaptation, distribution and reproduction in any medium or format, as long as you give appropriate credit to the original author(s) and the source, provide a link to the Creative Commons license and indicate if changes were made.

The images or other third party material in this chapter are included in the chapter's Creative Commons license, unless indicated otherwise in a credit line to the material. If material is not included in the chapter's Creative Commons license and your intended use is not permitted by statutory regulation or exceeds the permitted use, you will need to obtain permission directly from the copyright holder.

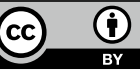

